\title{
Propulsion (mass movements) in the human colon and its relationship to meals and somatic activity
}

\author{
D. J. HOLDSTOCK, J. J. MISIEWICZ, T. SMITH, AND E. N. ROWLANDS \\ From the Medical Research Council Gastroenterology Unit, Central Middlesex Hospital, London
}

SUMmaRY Propulsive activity of the human colon was measured with radiopaque markers (shapes), radiotelemetering capsules, Perspex capsules containing ${ }^{51} \mathrm{Cr}$, or with free ${ }^{51} \mathrm{Cr}$ sodium chromate.

Propulsive activity can be readily detected by these techniques, none of which requires the use of radiological contrast media. With capsules containing ${ }^{51} \mathrm{Cr}$ or with free ${ }^{51} \mathrm{Cr}$ repeated observations can be made in the same patient without recourse to radiography. The patient can remain normally active during the test with encapsulated ${ }^{51} \mathrm{Cr}$. Repeated observations may also be made with shapes, if films exposed at low $\mathrm{mA}$ are used.

It was found that colonic intraluminal pressure activity rises markedly during and after food, but that in the resting patient this increase is rarely associated with propulsive activity. In physically active patients propulsion of colonic contents was significantly increased after meals. When colonic propulsion takes place, it does so by a series of mass. movements.

These results suggest that somatic activity is an important factor in the control of colonic transit in health or disease.

Intraluminal pressures in the colon can be accurately recorded with modern techniques, but the relationship between pressure and propulsive activity is not simple (Ritchie, Ardran, and Truelove, 1962; Holdstock, Misiewicz, and Waller, 1969). Transit rates through the colon have been less intensively studied than intraluminal pressures, although symptoms of disordered colonic propulsion are very common in clinical practice. The early radiological observations that faeces are propelled by mass movements (Holzknecht, 1909; Barclay, 1912; Case, 1913, 1915; Hertz and Newton, 1913) cannot now be repeated since the hazards of irradiation have become better known (MRC, 1960). Detailed analysis of colonic propulsive activity can be made with 
time-lapse cinefluorography (Ritchie, 1968a and b) but this sophisticated technique is unlikely to be generally available, whilst the standard radiological contrast media are unphysiological, may themselves affect the speed of transit (Alvarez and Freedlander, 1924), and the results cannot be analysed quantitatively.

We have accordingly used various alternative techniques for detecting propulsion of colonic contents. Since food may produce the symptoms of the irritable colon syndrome in some patients (Chaudhary and Truelove, 1962; Connell, Jones, and Rowlands, 1965), and since meals stimulate the colonic muscle to contract (Holdstock and Misiewicz, 1970), special attention has been paid to the relationship between food and propulsive activity and to the effect of somatic activity on colonic transit.

\section{Patients and Methods}

\section{PATIENTS STUDIED}

Brief clinical details of the 27 patients studied are given in Table I. In 19 patients with the irritable colon syndrome the tests were performed in the course of routine investigation of that condition, the remainder gave their informed consent to the tests; all were fully ambulant inpatients at the time of the studies.

\section{RADIOTELEMETERING OF INTRALUMINAL}

\section{PRESSURES AND RADIOGRAPHY}

Pressures were telemetered from the colon with radiocapsules (Rowlands and Wolff, 1960) as described previously (Connell, McCall, Misiewicz, and Rowlands, 1963; Misiewicz, Waller, and Eisner, 1966; Misiewicz, 1968a). Movements of the radiotelemetering capsule in relation to an aerial placed on the abdomen were detected by recording the strength of the signal broadcast by the capsule on a separate receiver (Misiewicz, Waller, Fox, Goldsmith, and Hunt, 1968b; Misiewicz, 1968a). The pressure records were analysed by the computer method of Misiewicz, Waller, Healy, and Piper (1968c). Variables of motility derived from computer analysis for the present study were motility index (MI) and percentage duration of activity (Misiewicz et al, 1968c). Two-way analysis of variance was used to test for significant differences between observation periods. Calculations involving the motility index were performed after conversion to logarithms, because of the log-normal distribution of those data.

Plain $x$-ray films of the abdomen were taken on fast film (Kodak) with the aid of high-speed intensifying screens (Kodak) and at low $\mathrm{mA}$, in order to minimize radiation dosage. It was necessary to use agrid to visualize the radioopaque shapes (see below) clearly, and for a patient of average build films were taken with an exposure of $0.35 \mathrm{sec}$ at $5 \mathrm{~mA}$ and $96 \mathrm{kV}$, so that the doseof radiation to the skin did not exceed $60 \mathrm{mR}$ per film. Women of childbearing age were excluded $\overline{\bar{c}}$. from the studies, and a gonad shield was used inळ the younger male patients. A radioopaque marker was taped over the umbilicus to help in the cen-s tering of the films.

MEASUREMENT OF PROPULSIVE ACTIVITY

Four techniques were used to measure the pros pulsive activity of the colon.

1 The position of the radiotelemetering capsules in the colon was ascertained on plain radioito graphs taken at predetermined intervals during the study. The radiocapsules measured 2.0 by $0.9 \mathrm{~cm}$ and had a specific gravity of 1.63 to $\vec{T}$ $1.84 \mathrm{~g} / \mathrm{cm}^{3}$.

2 Total transit time (from mouth to anus) andE radiographic detection of movement of colonic contents were studied with barium-impregnated polythene pellets (Halls, 1965; Hinton, 1966), which are referred to as 'shapes'. The cylindricaP shapes had a height and diameter of $0.3 \mathrm{~cm}$; theiro specific gravity was $1.03 \mathrm{~g} / \mathrm{cm}^{3}$.

3 The radionuclide ${ }^{51} \mathrm{Cr}$, in the form of sodiump chromate, was used as an alternative marker foọ colonic contents. Sodium chromate, which is not absorbed from the intestine (Hansky and Connell, $\overrightarrow{0}$ 1962), was given in the free form in a dose of $200 \mu \mathrm{Ci}$, and the following day abdominal scintigraphs were made with a 5-inch gamma. camera (Ekco Electronics). The scintigraph ande the field surveyed were photographed on the same polaroid film in a manner similar to that described by Thompson, Boyle, McGirr, and Tilston (1964). To obtain satisfactory records it was necessary to use the camera with a $\frac{3}{16}$-inch pinhole collimator approximately $20 \mathrm{~cm}$ from? the abdomen, and 10-15 min were required to? build up an acceptable scintigraph.

$4{ }^{51} \mathrm{Cr}$ as sodium chromate in a dose of 5 to ${ }^{\circ}$ $10 \mu \mathrm{Ci}$ was also used as a marker enclosed in of Perspex capsule $1 \mathrm{~cm}$ in diameter, similar to thosêస described by Ramsay (1965) and by Rosswicko Stedeford, and Brooke (1967). The position of the capsule was determined by a collimated scintilla tion counter (Ekco Electronics, type N559C), coupled to a ratemeter (Ekco Electronics, type N522C). Preliminary tests with a phantom? indicated that the capsule could be localized by this means to a circle of $5 \mathrm{~cm}$ diameter. The position of the capsule was charted with references to bony landmarks on a Perspex sheet laid om the abdomen, with the patient in the supine position. The plot was later transferred onto graph paper and the distance separating successive localizations was measured. The Perspex capsule was rendered radioopaque by painting it with Micropaque suspended in vinyl cement, so that localization could be confirmed on $x$-ray films 


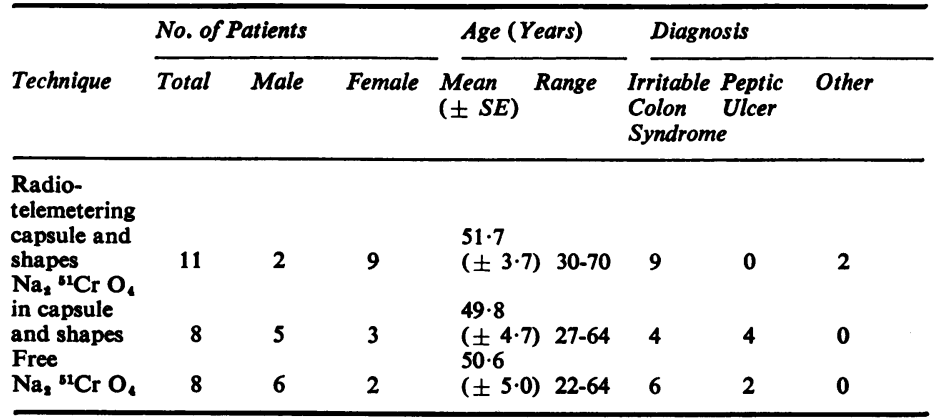

Table I Clinical details of patients studied

\begin{tabular}{llll}
\hline Site & First Meal & $\begin{array}{l}\text { Subsequent } \\
\text { Meal }\end{array}$ & Total \\
\hline $\begin{array}{l}\text { Ascending } \\
\text { colon }\end{array}$ & 8 & 5 & 13 \\
$\begin{array}{l}\text { Transverse } \\
\text { colon }\end{array}$ & 1 & 1 & 2 \\
$\begin{array}{l}\text { Descending } \\
\text { colon }\end{array}$ & 2 & 2 & 4 \\
Total & 11 & 8 & 19 \\
\hline
\end{tabular}

Table II Sites of pressure recording (11 patients)

\begin{tabular}{|c|c|c|c|c|c|c|c|c|}
\hline \multirow[b]{3}{*}{ Variable } & \multicolumn{7}{|c|}{ Observation Periods } & \multirow{3}{*}{$\begin{array}{l} \pm S E \\
\text { of Mean }\end{array}$} \\
\hline & \multicolumn{3}{|c|}{ Pre-meal } & \multirow[t]{2}{*}{ Meal } & \multicolumn{3}{|c|}{ Post-meal } & \\
\hline & 1 & 2 & 3 & & 1 & 2 & 3 & \\
\hline MI (loss) & 0.97 & 0.82 & 0.87 & 1.61 & $1 \cdot 47$ & 1.64 & 1.44 & $\pm 0 \cdot 12$ \\
\hline $\begin{array}{l}\text { Percentage } \\
\text { activity }\end{array}$ & $12 \cdot 7$ & $10 \cdot 5$ & $15 \cdot 3$ & $35 \cdot 4$ & $25 \cdot 0$ & $32 \cdot 4$ & $23 \cdot 7$ & $\pm \mathbf{3 \cdot 3}$ \\
\hline
\end{tabular}

Table III Colonic pressure activity before, during, and after a standard meal (means $\pm S E$ )

or at fluoroscopy. The specific gravity of the capsule was $1.22 \mathrm{~g} / \mathrm{cm}^{8}$.

TEST MEALS

Standard test meals were used in the radiotelemetering and radioisotope studies. Breakfast, lunch, and supper were approximately isocaloric. Protein, carbohydrate, fat, and fluid content were the same for all the meals.

\section{Results}

COMBINED RADIOTELEMETERING AND TRANSIT STUDY

Eleven patients (Table I) were given 25 shapes at the same time as a radiotelemetering capsule

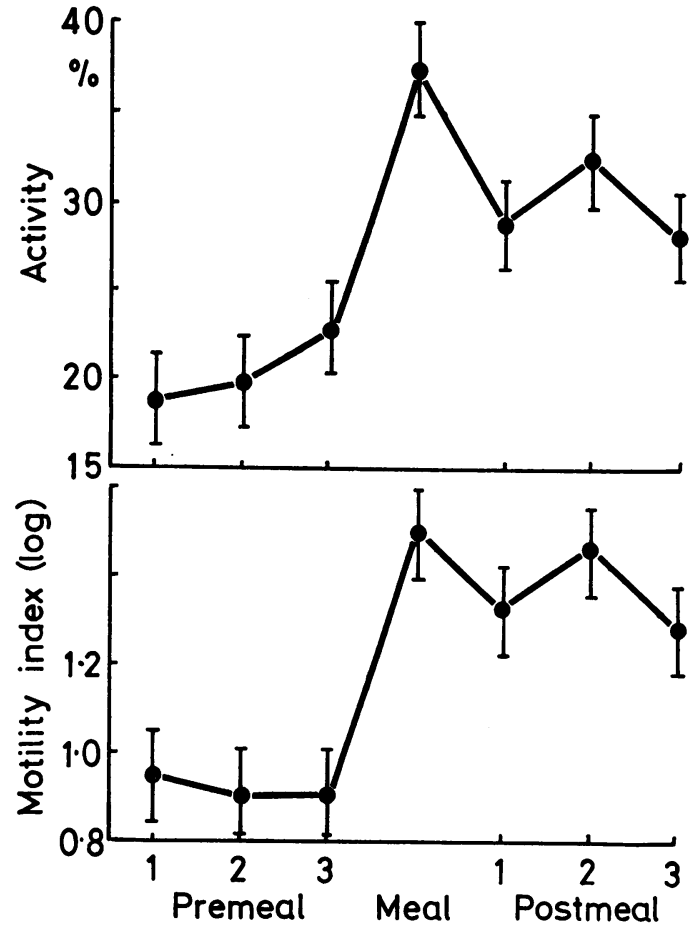

Fig. 1 Changes in motility index (MI) and percentage duration of activity during and after meals (bars $= \pm S E$ of means).

\begin{tabular}{lcc}
\hline Variable & $\begin{array}{l}\text { Meal v Mean } \\
(\text { Pre-meal 1, 2,3) }\end{array}$ & $\begin{array}{l}\text { Mean (Post-meal 1, 2,3) } \\
\text { v Mean (Pre-meal 1, 2,3) }\end{array}$ \\
\hline $\begin{array}{l}\text { MI (log) } \\
\text { Percentage }\end{array}$ & $0.72^{2} \pm 0.24$ & $0.63^{2} \pm 0.17$ \\
activity & $22.6^{2} \pm 6.9$ & $14.2^{2} \pm 4.9$ \\
\hline
\end{tabular}

Table IV Differences between observation periods (first meals only)

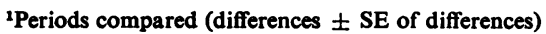

$$
\begin{aligned}
& i_{p}<0.01 \\
& i p<0.001
\end{aligned}
$$

on the evening preceding the test. When the latter was in the colon as judged by the character of the pressure record (Misiewicz et al, 1968b), a plain radiograph of the abdomen was taken and intracolonic pressures were recorded for one hour. At the end of this time a second plain radiograph was taken. Pressure recording continued while the patient ate a meal and for a further hour from the start of the meal; a third radiograph was then taken. The pressure activity, recorded during the meal, and in three consecutive 10-min periods preceding and following the meal, was analysed. Nineteen meals were studied in this way in the 11 patients, one having three meals, six having two, and four one meal. The sites in the colon from which pressures were recorded are listed in Table II, but as results from all the sites showed a similar trend, they were analysed together. However, in order to avoid bias, only the observations relating to the first meal in each 


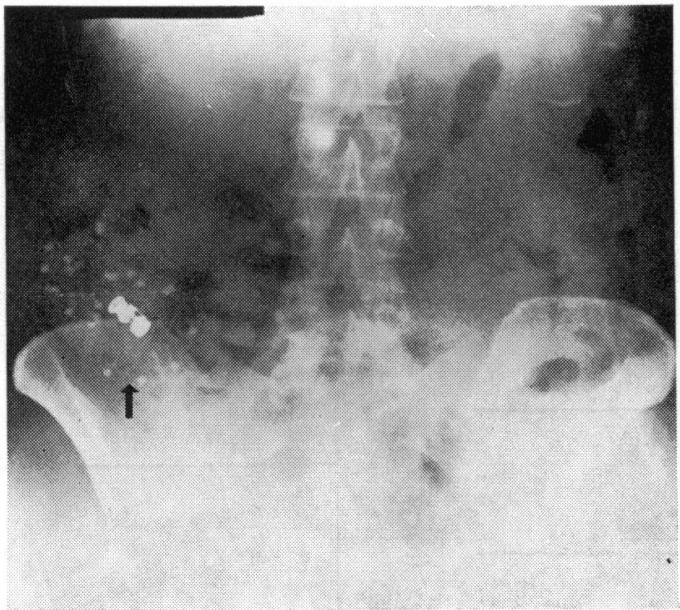

patient were submitted to statistical analysis.

Results of analysis of the pressure records for $\stackrel{\bigodot}{\rightleftharpoons}$ the 11 first meals in the 11 patients are summarized $\underset{\vec{c}}{\vec{\rho}}$ in Table III and in Figure 1. There were no $\frac{7}{0}$ significant differences in activity during any of the $\frac{\mathrm{C}}{0}$ three pre-meal observation periods, indicating $\frac{\overline{\bar{\omega}}}{\overline{\mathrm{s}}}$ that the observations were adequately controlled. $\vec{\nabla}$ Both variables of motility were significantly raised during and after the meal (Table IV); ${ }^{\infty}$ there were no significant differences between $\overrightarrow{0}$ the meal and post-meal periods or between individual post-meal periods.

Despite this undoubted increase in pressureco activity, propulsive activity was detected after only one of the 19 meals studied in this series, ie, in a patient with the irritable colon syndrome following a first meal. The abdominal film of this

Fig. 2a

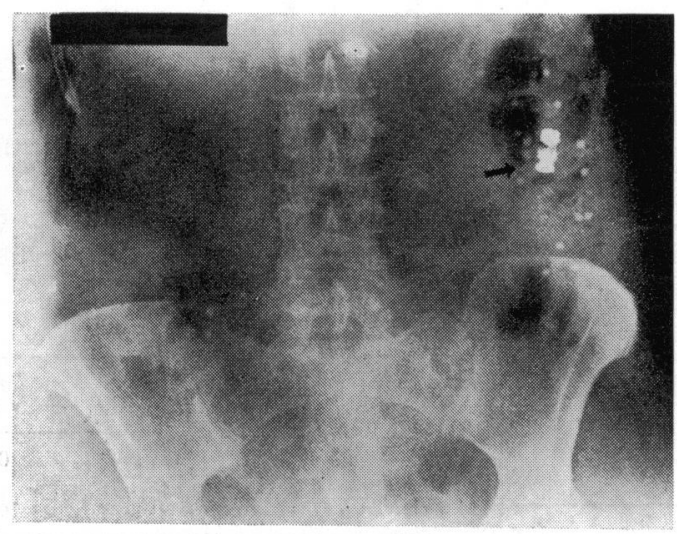

Fig. 2 Mass movement in the colon recorded by radiotelemetering capsule and shapes.

(a) Abdominal radiograph before start of meal. Arrow marks capsule and shapes.

(b) Abdominal radiograph one hour later.

(c) Telemetered record of capsule movement (upper trace) and intraluminal pressure (lower trace, pressure scale in $\mathrm{cm} \mathrm{H}_{2} \mathrm{O}$ ) beginning 15 min before the film in (b). Capsule movement occurs soon after the vertical line and the progressive decrease in signal strength on the movement trace indicates increasing distance between radiocapsule and the receiving aerial.

Fig. $2 b$

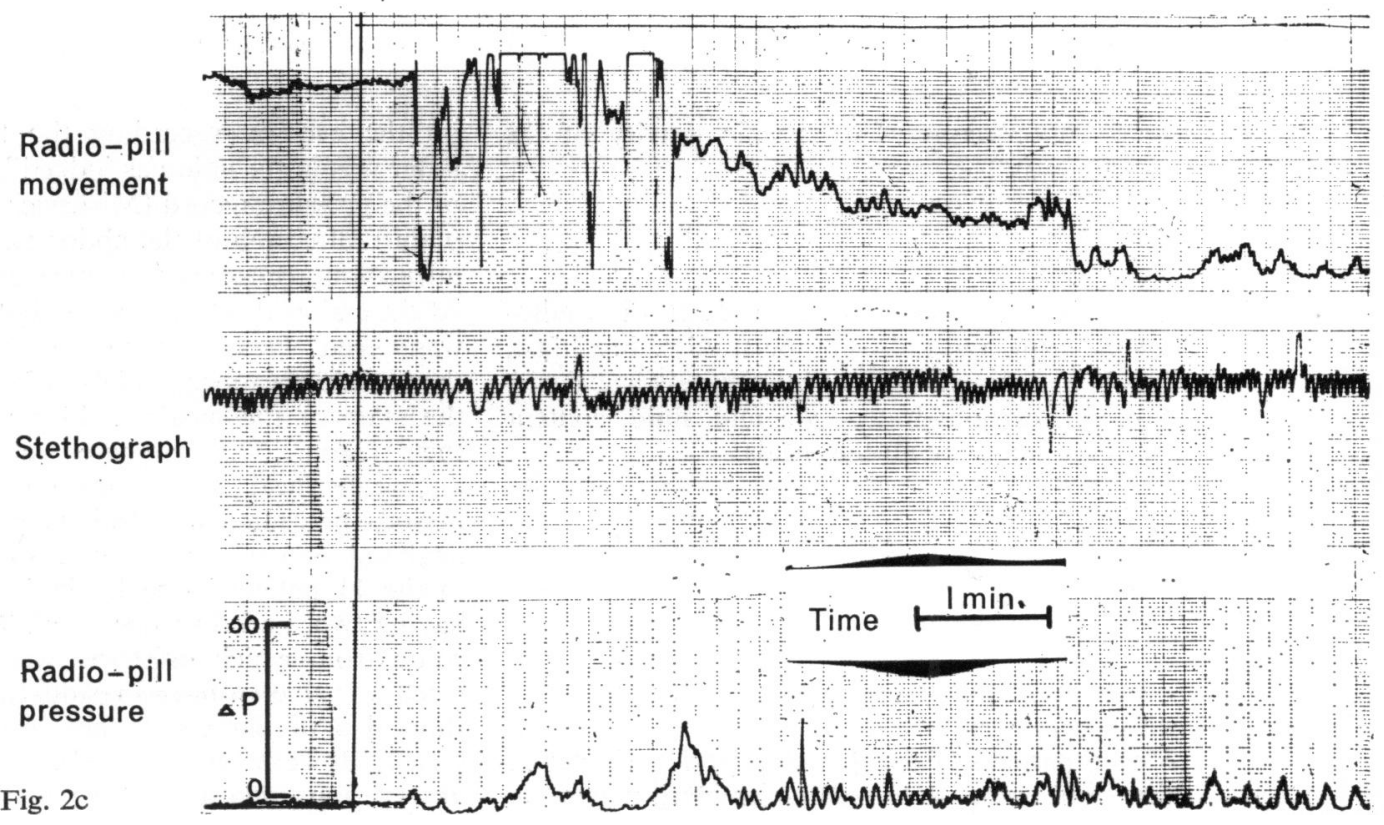


patient immediately before the meal is shown in Fig. 2a; there was no change in the position of the markers between this and the first film taken one hour previously. In the third film taken one hour after starting the meal, the radiotelemetering capsule and the shapes moved from their original position in the caecum to the descending colon (Fig. 2b). The telemetered record approximately $15 \mathrm{~min}$ before the third film (Fig. 2c) suggests that the movement of the radiotelemetering capsule lasted a few minutes at most and was not accompanied by striking pressure activity. It should be borne in mind, however, that a freely mobile radiotelemetering capsule in the bowel lumen is unlikely to record pressure changes which result in the propulsion of the radiotelemetering capsule. The patient experienced no symptoms or desire to defaecate during this period.

Mouth-to-anus transit times of the radiotelemetering capsule and of the shapes (Table V) were closely comparable, and in general the capsule was passed in the stool containing the greatest number of shapes. The transit time of the

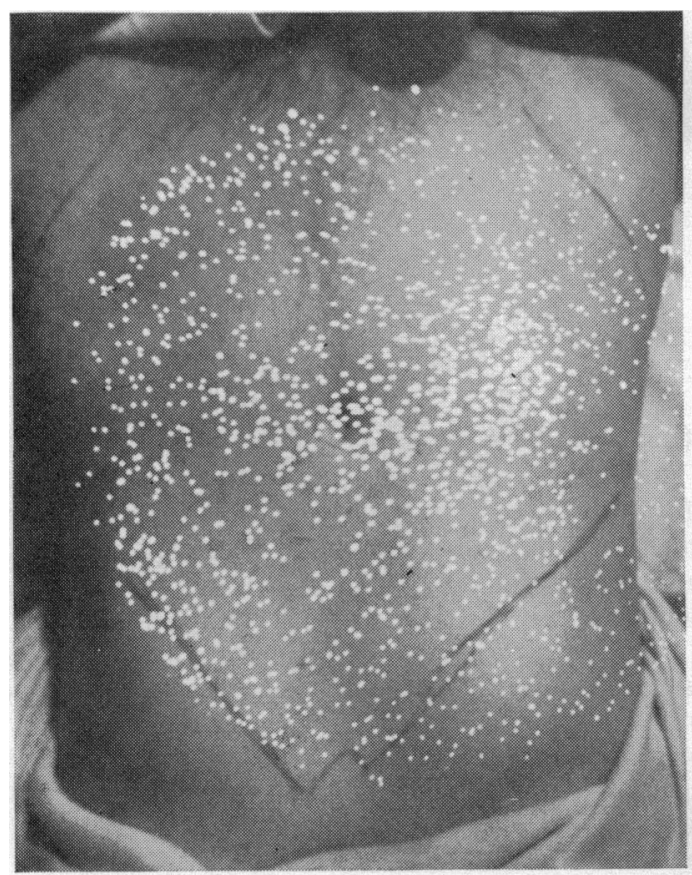

Fig. 3a

Fig. 3 Gamma scintigraphs of free sodium chromate $\left.{ }^{(51} \mathrm{Cr}\right)$ in the colon (a) before, and (b) after, lunch, showing propulsion of the radioisotope bolus. pill and shapes were faster than average (20 and propulsive activity was detected.

\section{STUDIES OF PROPULSION WITH FREE}

${ }^{51}$ CR SODIUM CHROMATE

The suitability of free labelled sodium chromate as a marker of colonic propulsion was studied in eight patients (Table I). Of the isotope,

\begin{tabular}{|c|c|c|c|c|}
\hline \multirow[b]{3}{*}{$\begin{array}{l}\text { Radiotelemetering } \\
\text { capsules }\end{array}$} & \multirow[b]{2}{*}{$\begin{array}{l}\text { No. of } \\
\text { Patients }\end{array}$} & \multicolumn{3}{|c|}{ Transit Time $(h r)$} \\
\hline & & Mean & $( \pm S E)$ & Range \\
\hline & \multirow{2}{*}{11} & $57 \cdot 9$ & $( \pm 14 \cdot 0)$ & $15-180$ \\
\hline $80 \%$ of shapes & & $63 \cdot 1$ & $( \pm 13.6)$ & $15-185$ \\
\hline${ }^{51} \mathrm{Cr}$ capsules & \multirow{2}{*}{8} & 62.9 & $( \pm 15 \cdot 6)$ & $14-137$ \\
\hline $80 \%$ of shapes & & $67 \cdot 0$ & $( \pm 17 \cdot 4)$ & $14-137$ \\
\hline
\end{tabular}

Table V Comparison of transit times of radiotelemetering capsules or ${ }^{51} \mathrm{Cr}$ capsules with shapes administered simultaneously 33 hours respectively) in the patient in whom

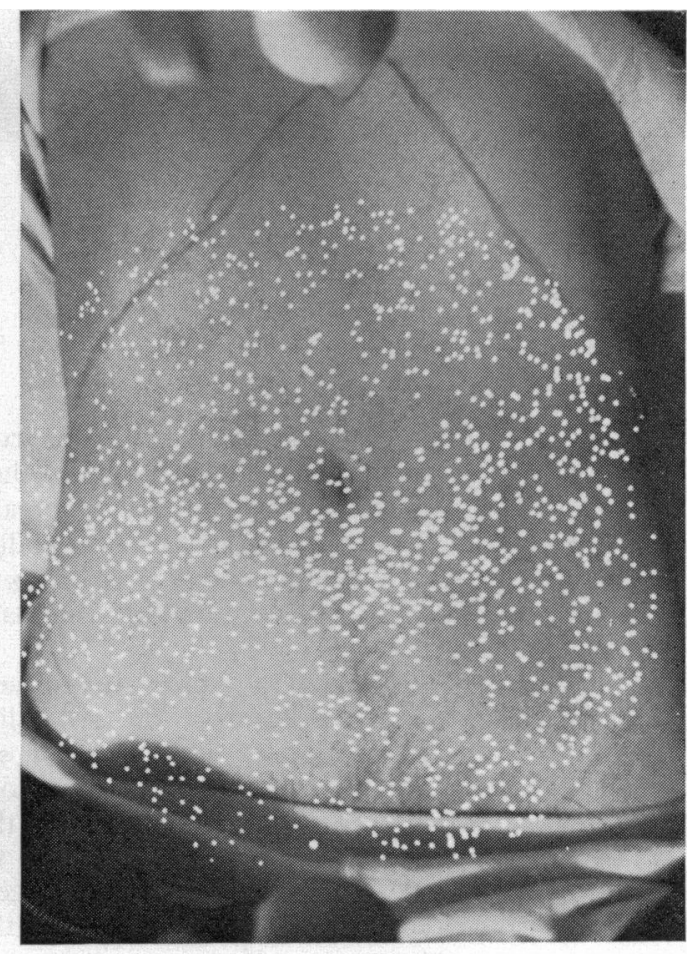

Fig. 3b 


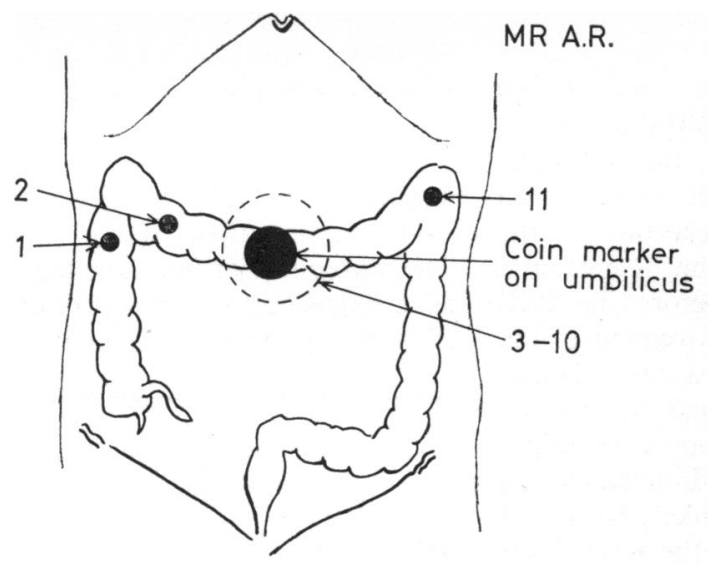

Fig. 4a

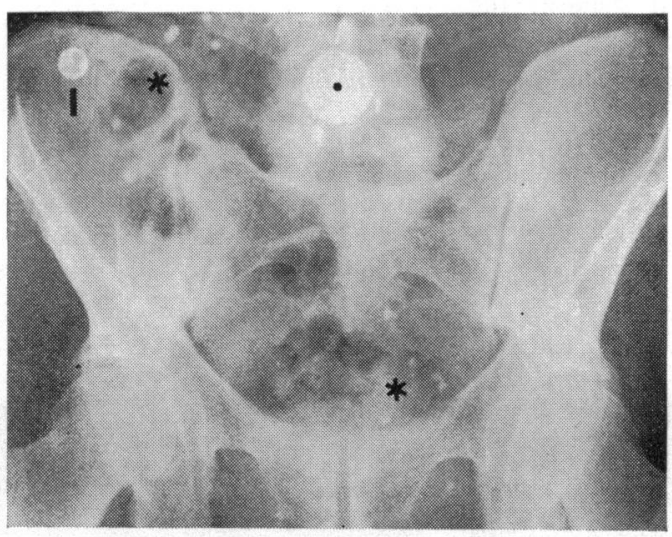

Fig. 4b

$200 \mu \mathrm{Ci}$ was administered in fruit juice with the evening meal the day before the study, and the following morning a light breakfast was given. Gamma scintigraphs of the abdomen were made at hourly intervals for up to six hours, and after the second scintigraph the patient was given lunch.

In two of the eight patients there was no detectable concentration of the radioisotope in the colon; both of these passed a soft stool on the morning of the study and although these stools were not collected, it is likely that much of the radioisotope was eliminated at this time. In the remaining six patients a concentration of the radioisotope was apparent in the ascending or transverse colon; an example is shown in Fig. 3a, where the radioisotope is concentrated to the right of the umbilicus. A change in the position of the radioisotope was detected only

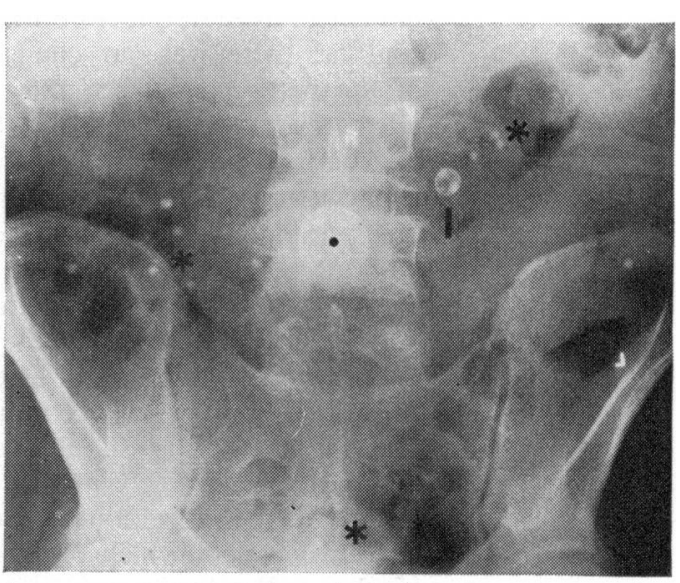

Fig. 4c

Fig. 4 (a) Plot of a Perspex capsule containing $5 \mu \mathrm{Ci}$ of ${ }^{51} \mathrm{Cr}$ located at hourly intervals by scintillation counter. Figures refer to successive localizations.

(b) and (c) X-ray films corresponding to localization 1 and $3 .^{*}=$ shapes; $=$ capsule; $=$ marker on umbilicus.

once (Fig. 3b). Scintigraphic appearances in the field outside the colon were due to background activity and not to residual radioisotope elsewhere in the abdomen.

One patient had a bowel action during the test while the radioisotope was in the transverse colon, but there was no change in the position of the marker bolus after defaecation.

\section{STUDIES OF PROPULSION WITH ${ }^{51} \mathrm{CR}$} SODIUM CHROMATE IN CAPSULE AND WITH SHAPES

Eight patients received $5-10 \mu \mathrm{Ci}$ of $\mathrm{Na}_{2}{ }^{51} \mathrm{Cr} \mathrm{O}_{4}$ sealed in the Perspex capsule, which was swallowed together with 25 shapes at supper time on the evening before the test. The following day the capsule was located hourly with a scintillation counter linked to a ratemeter, and radiographs 
were taken two hourly to check the accuracy of the localizations. Standard meals were given at four-hourly intervals. In practice it was found that the patients did not usually begin to eat until nearly half way between observations, and in analysing the results the meal hour, postmeal hour, and other hours have been tabulated separately. Propulsive activity was defined as a change of $5 \mathrm{~cm}$ or more in the position of the capsule, or if a bowel action took place.

There was always good agreement between the radiographic and the scintillation counter observations. Localizations performed with the latter technique left little doubt as to whether movement of the capsule took place. Radiographs showed that propulsion of the shapes was always accompanied by the movement of the capsule.

Propulsion was recorded during 17 of 19 hours' observation in all the eight patients. There were 16 instances of capsule movement and five bowel actions, one of which contained a capsule. Propulsion increased significantly during the hour following the meal when compared with the other hours (all propulsive activity, $\chi^{2}=9.86$, $P<0.01$; capsule movements only, $\chi^{2}=6.91$, $P<0.05$ ). Excluding the capsule passed per rectum and another passing through the splenic flexure, the mean distance traversed by the capsules during the remaining 14 propulsive movements was $10.3 \mathrm{~cm}$ (SE \pm 1.5 ; range 5 to $22 \mathrm{~cm}$ ). These figures are probably an underestimate, as the colon was assumed to be straight between two successive localizations. An example of capsule propulsion is shown in Figs. $4 a, b$, and c. Two examples of retropulsion of the capsule were observed, both in periods immediately after propulsion.

Transit times from mouth to anus for shapes and capsules given simultaneously were similar (Table V). In six of the eight patients the stool in which the capsule was passed also contained the largest number of shapes. The handling of the capsule by the gastrointestinal tract can therefore be regarded as similar to that of the shapes.

\section{Discussion}

\section{TECHNIQUES}

Free ${ }^{51} \mathrm{Cr}$ sodium chromate is particularly appealing as the most physiological marker for following the progress of colonic contents, but adequate concentration of the radioisotope in the colon seems difficult to attain in the presence of bowel looseness. Improved scintigraphs may be possible with a larger $\gamma$-camera that was available, but with an inevitable increase in the cost of equipment. At the present time, therefore, the radiopaque shapes (Halls, 1965; Hinton, 1966; Hinton, Lennard-Jones, and Young, 1969) appear to be the most universally applicable clinical method for measurement of colonic or of total transit time, and have already yielded interesting data on colonic propulsion in constipated patients (Hinton and Lennard-Jones, 1967). The combination of shapes with radiographs exposed at low $\mathrm{mA}$ extends the scope of the technique for measuring colonic propulsion, but in order to minimize the dose of radiation the quality of the films is deliberately sacrificed and contrast kept to the minimum required for the confident identification of shapes. The present work shows that shapes combined with films exposed at suitable intervals can be used to follow the progress of colonic contents in patients who are normally active between the observations.

The ${ }^{51} \mathrm{Cr}$-labelled Perspex capsule has transit times similar to the shapes, which in turn behave similarly to sodium chromate or carmine (Hinton et al, 1969), despite the higher specific gravity of the capsules which might be expected to delay transit (Hoelzel, 1930). Encapsulated ${ }^{131}$ I used by Rosswick et al (1967) or ${ }^{57} \mathrm{Co}$, employed by Ramsay (1965), are alternatives to encapsulated ${ }^{51} \mathrm{Cr}$ with no particular advantages or disadvantages. The movement of radioisotopically labelled capsules can be followed without recourse to radiography, there being virtually no limit to the number of localizations that can be performed in the course of a particular study. Prolonged observations of colonic propulsive activity can thus be made without appreciable radiation dose to the patient. However, difficulties in localization of the Perspex capsule can sometimes occur, for example, in differentiating between the terminal ileum or caecum, and when the transverse colon is low lying the distinction from the sigmoid can be impossible. In such patients, a plain abdominal radiograph, or brief screening, will usually resolve doubts as to the location of the radioactive source. Neither the shapes, nor free or encapsulated ${ }^{51} \mathrm{Cr}$, however, can be used to measure transit through the small intestine.

These difficulties are avoided if the radiochromium source is included in the standard radiotelemetering capsule, so that while the location of the latter is deduced from the characteristics of the telemetered pressure record (Misiewicz et al, 1968c) propulsive activity is simultaneously monitored with the collimated scintillation counter. In this way the necessity for radiographic control is eliminated altogether, and the method has been used successfully for measurement of propulsion not only in the colon, but also in the small intestine (Misiewicz, Waller, Kiley, and Horton, 1969). Transit times of radiotelemetering capsules correlate well with shapes; moreover, the ability to differentiate between the small and large intestine and the absence of $x$-ray irradiation are considerable advantages. Localization of the radiotelemetering capsule using a radionuclide appears preferable to the elaborate servo-tracking system developed by 
Jacobson (1962), partly because it is simpler, but mainly because it avoids strict immobilization of the patient. The technique might therefore be useful for assessing the relative importance of abnormal small intestinal motility in patients with the irritable bowel syndrome or undiagnosable abdominal pain; it is also eminently suitable for subjects in whom it is desirable to avoid $x$-ray exposure. On the other hand, correlation of the telemetered pressures with propulsive activity is complicated not only by changes in the position of the capsule, but also because pressures are measured with only a single sensor. A radiotelemetering capsule therefore may not register the pressure within the segment of colon involved in a mass movement as defined by the earlier radiologists. A chain of balloons or of open-ended tubes would be necessary to record pressures (as distinct from propulsion) during a mass peristalsis.

\section{RESULTS}

The present results confirm, after a lapse of 50 years, the early radiologists' reports (Holzknecht, 1909; Barclay, 1912) that colonic contents progress distally by a series of infrequent large movements, known as mass movements or mass peristalsis. The techniques used in this study provide for the first time a means of recording permanently this type of colonic activity without the use of radiological contrast media. Permanent records can be made with time-lapse cinefluorography (Ritchie, 1968a and b) or on videotape, but it is likely that acceptable limits of radiation dosage will always severely curtail the time during which colonic behaviour can be observed radiologically. On the other hand time-lapse cinefluorography allows for a more detailed examination of colonic activity than is possible with capsules or shapes, but the patient must remain at rest in the recumbent posture during the study, the interpretation of minor movements of colonic wall is difficult, and an unphysiological marker (barium sulphate) is used.

Perhaps the most important observation in the present study is that somatic activity is a variable which should be taken into account in any investigation of colonic transit. This conclusion is suggested by considering the effect of meals on colonic pressures and propulsion under various conditions. On the basis of the present data a clear distinction can be made between segmenting pressure activity on the one hand, and propulsive activity on the other, and the results are in this respect in agreement with those of other authors (Ritchie et al, 1962; Ramorino and Colagrande, 1964). Both in this and in another study with patients resting on a couch (Holdstock and Misiewicz, 1970) there was a marked rise in segmenting activity of the bowel during, and after, meals, but propulsion of the radiotelemetering capsule was rarely observed. Similarly in our studies using free ${ }^{51} \mathrm{Cr}$ sodium chromate, where patients spent a considerable time lying on the $\gamma$-camera table or resting in a chair between the scintiscans, the position of the radioactive bolus remained unaltered, with only one exception.

These observations contrast strongly with results of the tests with the ${ }^{51} \mathrm{Cr}$ capsules, in which propulsion was much more often recorded, and in which there was a significant rise in propulsive activity after meals. The main difference between the tests with the ${ }^{51} \mathrm{Cr}$ capsules and the other studies was that the patients remained physically active between the successive localizations of the capsules, including a short walk from the ward to the laboratory at hourly intervals. Apart from the time during which localizations were performed, this also meant that the patients were removed from the possibly stressful experimental environment, except for the brief observation periods.

Moreover, in two patients not included in this report because the pressure records or the radiographs were technically unsatisfactory, the radiotelemetering capsule and shapes remained in the descending colon during two hours' immobilization on a couch, but were passed in the stools within a few minutes of returning to the ward. In other studies, radiotelemetering capsules remained stationary in the caecum for long periods, only to be passed in the stool on the return of the patients to the ward.

These observations suggest that somatic movement affects the propulsion of colonic contents and must be considered a factor in the control of motility together with other stimuli, such as the entry of food into the small intestine (Holdstock and Misiewicz, 1970), although the mechanism of this effect is not clear. They might also explain why Holzknecht (1909) was able to observe mass movement on only two occasions in the course of more than 1,000 barium enema examinations. The data obtained under experimental conditions correlate well with the characteristic early morning diarrhoea of ulcerative colitis or of the irritable colon syndrome, and with the well known clinical finding that inactivity tends to produce constipation (Jones, Gummer, and Lennard-Jones, 1968). The present results may also explain why rest in bed is beneficial in diarrhoeal states. Further studies are needed to determine whether these reflexes are more active or more frequent in patients who suffer from diarrhoea. The often experienced call to stool after breakfast might be produced by a combination of gastric emptying and somatic activity triggering off mass peristalsis, with resultant entry of faeces into the rectum and initiation of defaecation in those who have early conditioned themselves to respond.

We thank Dr F. Avery Jones and Dr T. D. Kellock for permission to study their patients, Dr E. S. Williams for access to, and Dr R. F. Harvey for help with, the gamma-camera in the Department of $\mathrm{Nu}$ - 
clear Medicine at the Middlesex Hospital. We are grateful to Miss J. Fletcher for devising the standard test meals, Mr W. S. Taylor for advice on radiographic technique, Miss Nancy Kiley, BSc, Mrs G. D. Lamble and Mrs E. E. Cox for technical assistance, and to Mr F. Booker, FPS, for the photography.

\section{References}

Alvarez, W. C., and Freedlander, B. L. (1924). The rate of progress of food residue through the bowel. J. Amer. med. Ass., $83,576-580$.

Barclay, A. E. (1912). A note on the movements of the large intestine. Arch. Roentg. Ray., 16, 422-424.

Case, J. T. (1913). X-ray observations on colonic peristalsis and antiperistalsis. Proc. 17th International Congress of Medicine (Section XXII, Radiology, Part II), 11-42. Henry Frowde, London.

Case, J. T. (1915). The x-ray investigation of the colon. Arch. Roentgen. Ray, 19, 375-387.

Chaudhary, N. A., and Truelove, S. C. (1962). The irritable colon syndrome. Quart. J. Med., N.S., 31, 307-322.

Connell, A. M., McCall, J., Misiewicz, J. J., and Rowlands, E. N. (1963). Observations on the clinical use of radiopills. Brit. med. J., 2, 771-774.

Connell, A. M., Jones, F. A., and Rowlands, E. N. (1965). Motility of the pelvic colon. IV Abdominal pain associated with colonic hypermotility after meals. Gut, 5, 105-112.

Halls, J. M. (1965). Bowel content shift during normal defaecation. Proc. roy. Soc. Med., 58, 859-860.

Hansky, J., and Connell, A. M. (1962). Measurement of gastrointestinal transit using radioactive chromium. Gut, 3, 187-188.

Hertz, A. F., and Newton, A. (1913). The normal movements of the colon in man. J. Physiol. (Lond.), 47, 57-65.

Hinton, J. M. (1966). A new method for measuring gut transit times. Gut, 7, 718.

Hinton, J. M., and Lennard-Jones, J. E. (1967). Gastrointestinal transit in constipation. Gut, 8, 633 .

Hinton, J. M., Lennard-Jones, J. E., and Young, A. C. (1969). A new method for studying gut transit times using radiopaque markers. Gut, 10, 842-847.

Hoelzel, F. (1930). The rate of passage of inert materials through the digestive tract. Amer. J. Physiol., 92, 466-497.

Holdstock, D. J., Misiewicz, J. J., and Waller, Sheila L. (1969). Observations on the mechanism of abdominal pain. Gut, 10, 19-31.

Holdstock, D. J., and Misiewicz, J. J. (1970). Factors controlling colonic motility: colonic pressure and transit changes after meals in patients with total gastrectomy, pernicious anaemia or duodenal ulcer. Gut, next paper in this issue.

Holzknecht, G. (1909). Die normale peristaltik des kolon. Münch. med. Wschr., 56, 2401-2403.

Jacobson, B. (1962). Tracking radiopills in the human body. New Scientist, 13, 288-290.

Jones, F. A., Gummer, J. W. P., and Lennard-Jones, J. E. (1968). Clinical Gastroenterology, p. 69. 2nd Ed., Blackwell, Oxford.

Medical Research Council (1960). The hazards to man of nuclear and allied radiations. 2 nd report. cmnd. 1225. H.M.S.O., London.
Misiewicz, J. J., Waller, Sheila L., and Eiser, E. (1966). Motor responses of human gastrointestinal tract to 5-hydroxytryptamine in vivo and in vitro. Gut, 7, 208-216.

Misiewicz, J. J. (1968a). Measurement of intraluminal pressures. Radiotelemetry, design of manometric studies and computer analysis of results. Amer. J. dig. Dis., N.S., 13, 389-396.

Misiewicz, J. J., Waller, Sheila L., Fox, R. H., Goldsmith, R., and Hunt, T. J. (1968b). The effect of elevated body temperature and of stress on the motility of the stomach and colon in man. Clin. Sci., 34, 149-159.

Misiewicz, J. J., Waller, Sheila L., Healy, M. J. R., and Piper, E. A. (1968c). Computer analysis of intraluminal pressure records. Gut, 9, 232-236.

Misiewicz, J. J., Waller, Sheila L., Kiley, Nancy, and Horton, E. W. (1969). The effect of oral prostaglandin $E_{1}$ on gastrointestinal transit in man. Lancet, 1, 648-651.

Ramorino, M. L., and Colagrande, C. (1964). Intestinal motility. Preliminary studies with telemetering capsules and synchronised fluorocinematography. Amer. J. dig. Dis., N.S., 9, 64-71.

Ramsay, G. S. (1965). Progress of a marker in the large intestine. Dis. Colon Rect., 8, 74-75.

Ritchie, J. A. (1968a). Colonic motor activity and bowel function. Part I. Normal movement of contents, Gut, 9, 442-456.

Ritchie, J. A. (1968b). Colonic motor activity and bowel function. Part II Distribution and incidence of motor activity at rest and after food and carbachol. Gut, 9, 502-511.

Ritchie, J. A., Ardran, G. M., and Truelove, S. C. (1962). Motor activity of sigmoid colon of humans. A combined study of intraluminal pressure recording and cineradiography. Gastroenterology, 43, 642-668.

Rosswick, R. P., Stedeford, R. D., and Brooke, B. N. (1967) New methods of studying intestinal transit times. Gut, 8, 195-196.

Rowlands, E. N., and Wolff, H. S. (1960). The radiopill Telemetering from the digestive tract. Brit. Commun. Electron. 7, 598-601.

Thompson, J. A., Boyle, J. A., McGirr, E. M., and Tilston, D. R. G. (1964). Clinical trial of modified gamma camera for thyroid scanning. Lancet, 2, 714-716. 


\section{Notes and activities}

On 30 September 1969, 23 European gastroenterologists met at the University of Erlangen medical clinic to found the European Gastro Club (E.G.C.). This association is not intended to increase the already large number of national and international societies, but rather to be an informal society of leading European gastroenterologists and provide them with the maximum information on the results of current investigations carried out by other groups. The aims of the club are to divide its members into a number of working groups and to cooperate in certain scientific problems on a supraregional basis.

Further details can be obtained from Professor L. Demling, director of the Medizinische Klinik mit Poliklinik, 8520 Erlangen, Krankenhausstrasse 12, Postfach 266 , Germany.

Progress in Pancreatology, the proceedings of the third symposium of the European Pancreatic Club, held in Prague from 2 to 4 July 1968 has been published by the Czechoslovak Medical Press, Prague. Edited by P. Fric, F. Mais, and R. Ronsky it costs US $\$ 5.00$.

Digestive Disease Week, the 1970 Annual General Meeting of the American Gastroenterological Association, will be held from 18 to 23 May at Wentworth-by-the-Sea, Portsmouth, New Hampshire, and the Sheraton-Boston Hotel, Boston, Massachusetts. The plenary session of the Association will be held on 22 and 23 May and will include the Presidential address, selected papers, the memorial lecture given by $\mathrm{Dr}$ W. D. M. Paton of Oxford University, England (May 22), and the presentations of the Friedenwald medal to $\mathrm{Dr}$ Andrew $\mathrm{C}$. Ivy and the Distinguished Achievement Award to Dr Alan F. Hoffmann (23 May). A postgraduate course: Pathophysiology of the biliary tract: from canalicus to Oddi will be chaired by Dr Franz Ingelfinger (18 and 19 May). The Gastroenterology Research Group Symposium: Enteric flora and infection will be held on 21 May in the afternoon, clinical symposia on oesophagal reflux, diverticular disease, immunology in the diagnosis of cancer of the alimentary tract, and nutrition will be held on the afternoon of 22 May. There will also be undergraduate teaching seminars taken by Drs James Carey and Warren Beeken (evening of 30 May) and a research forum (21 May). The American Society of Gastrointestinal Endoscopy will hold its meeting on 20 May. A reception and informal buffet will be held at the Sheraton-Boston on Thursday 21 May, followed by a concert.

Intestinal Absorption Information Centre The Office for Scientific and Technical Information (OSTI) have announced in their newsletter that they have awarded a grant of up to $£ 22,400$, over three years from 1 September 1969 to 31 August 1972, to the Intestinal Absorption Information Centre at the University of Sheffield. This project, which has received earlier OSTI support, was initiated by Professor D. H. Smyth FRS of the Department of Physiology and is a joint venture with Professor W. L. Saunders of the Postgraduate School of Librarianship and Information Service.

The newsletter goes on to say: 'The Centre has developed a monthly information service the "Intestinal Absorption Bulletin" (IAB) which is now supplied to over 300 subscribers at $£ 4$ a year. Basically a current awareness publication, the bulletin contains brief abstracts and has computer-produced author and subject indexes. During the period of the new grant the Centre will experiment with a number of additional services, related to physiology, directed at various sizes of user populations. Two areas having a potential user population similar to intestinal absorption are cell membrane structure and renal tubule function. The Centre will produce bulletins similar to IAB in these areas, with the close collaboration of subject experts. For smaller populations $(50-200$ scientists) the output of mechanized disciplinary services will be edited to form a bulletin in order to test whether this type of less sophisticated but comparatively inexpensive service is acceptable. An experiment to produce indexed special bibliographies in a number of subjects will also be mounted in order to evaluate their use as retrospective search tools. The demand for these services will be assessed by the willingness of users to pay for them, and the intention is to make the Centre self-supporting by the end of the grant period. In addition to these services the Centre will also provide an experimental MEDLARS liaison service to find out how far this activity can be integrated into the scope of a specialised information centre.

'Provision is also made in the grant for the continuation of the research in information retrieval techniques which the Centre has been conducting during the past three years. This will include a comparison of citation indexes with subject indexes as a retrieval system for specialised subjects, and the use of weighted terms for profile construction in mechanised services in order to identify methods for automatic construction of profiles.'

\section{Notes on boóks}

Biochemical Disorders in Human Disease edited by R. H. S. Thompson and I. D. P. Wootton (3rd edition) Churchill, London, 160s). This is now a classic publication and an essential reference book in all general and specialist libraries. In relation to gastroenterology there are the following chapters: 'Nutritional disorders' (R. Passmore and M. H. Draper), 'Diseases of the liver and biliary tract' (Noel R. Maclagan), 'Diseases of the gastro-intestinal tract' (O.M. Wrong, H. S. Wiggins, and I. D. P. Wootton), 'The pancreas' (Henry T. Howart). Indeed many other sections on lipidoses, anaemias, and amino-acid metabolism and biochemistry of malignant disease will be of value to gastroenterologists.

Cancer of the Digestive Tract, edited by C. Tilden and Warren H. Cole (380 pp, Butterworth, London, 64s), describes the incidence, clinical manifestations, pathology and progress, surgical detail and postoperative management of cancer of various sites, in the alimentary and biliary tracts. There are useful chapters on therapy, chemotherapy and radiotherapy. It is well produced and up-todate but it is not immediately clear for whom it is written. It is clearly of value as a reference book.

\section{Correction}

On page 95 (Gut, 11, 91-99) of the February issue we regret that Figure 3a is printed upside down, and in the legend to Figures $4 \mathrm{~b}$ and $4 \mathrm{c}$ the correct symbols are: * = shapes; I =capsule; $\mathbf{O}=$ marker on umbilicus. 
of modern medicine and the medical sciences'. Consultants in all fields will find this series gives them a really up-todate picture of basic sciences and their practical application in medical practice.

\begin{abstract}
Journées françaises d'informatique medicale et hospitalière. This publication brings together studies on physics and mathematics applied to medicine in France with special reference to mechanical documentation and use of computers. There is a section on computer diagnosis of liver diseases. Essentially a book for the super specialist in computeraided medicine. The book is published by Institut de recherche d'informatique et d'automatique, Rocquencourt, France. $50 \mathrm{Fr}$.
\end{abstract}

Surgical symposia tend to be unexpectedly good sources of gastroenterological papers. This is true for this symposium on unexpected complications of surgery published in volume 50, no. 2, April 1970, The surgical clinics of North America (W. B. Saunders Co., price 45s). There are contributions on duodenal diverticula, acute cholecystitis following surgery, phytobezoars following gastric surgery, and pancreatic pseudocysts. The sections on operative collapse after corticosteroid therapy, endotoxin shock, and on improving the survival of the critically ill surgical patient are of special general interest. Altogether a worthwhile symposium.

Smooth Muscle (Edward Arnold, £10). Twenty authors engaged in smooth muscle research have been brought together in this comprehensive and im- portant account of current activity in this field. The chapters have in fact all been written by people who, at one stage in their career have worked under Professor Edith Bülbring in the Department of Pharmacology at Oxford. This volume represents a milestone in our knowledge of this vital structure throughout the alimentary tract and will indeed serve as a useful review for workers in the field as well as a stimulus for future investigations.

Tumour Specific Transplantation Antigen is the title of this monograph of 78 pages (Heinemann, London, and SpringerVerlag, Berlin, Heidelberg, and New York). Tumour specific transplantation antigen has been demonstrated in a variety of experimental tumours, particularly those induced by oncogenic viruses and carbohydrate carcinogens. Although clear evidence cannot as yet be provided for human cancer, it has at least been shown that some human tumours will contain tumour specific transplantation antigen and that immune reactions against tumour specific transplantation antigen will also be elicited in man. This book by Pavel Koldovsky is one which should be read by all those concerned with cancer therapy or research.

Human Schistosomiasis by Peter Jordan and Gerald Webbe. This disease probably affects over 200 million people especially in Africa and South America. Today with so much world travel the disease is now increasingly seen in Europe and America, and most gastroenterologists will be coming in contact with it. This timely publication brings together present-day information about this disease to assist all those who have to deal with it. The book is pleasantly compact and read- able, and is well illustrated with a comprehensive bibliography.

Liver Disease. by A. Paton. Heinemann London, 30s. This slim monograph of 185 pages provides an introduction to present-day classification and ideas on mechanisms and treatment of liver diseases. It does not attempt to probe in depth but paints a broad canvas. It arose from a series of lectures for postgraduate students and for clinicians wishing to develop a greater interest in gastroenterology. This book provides a most useful introduction to problems which concern diseases of the liver. It succeeds splendidly in this objective.

Morphological and Physiological Aspects of Anal Continence and Defaecation, edited by R. Kerremans (Presses Academiques, Brussels). This is a study in depth of ano-rectal function. It presents a very detailed account of the anatomy of the pelvis, both macro and micro, and then describes the observations made using moulds of the anus in resected specimens. The scope and technique of cine radiography, of intraluminae pressure recordings and electromyography are all described in great detail and with reference to modern pharmacological advances concerning smooth and striated muscle. This monograph, with a foreword by A. M. Connell, is a book for physiologists and proctologists.

\section{Correction}

On page 95 (Gut, 11, 91-99) of the February issue we regret that Figure $3 a$ is printed upside down, and in the legend to Figures $4 b$ and $4 c$ the correct symbols are: * = shapes; $\mathbf{\square}=$ capsule; $\boldsymbol{0}=$ marker on umbilicus. 